\title{
Smart Specialization of the Region as a Tool for Modernizing Innovative Development
}

\author{
IRYNA VAKHOVYCH ${ }^{1 *}$, BAKTYGUL SATYVALDIEVA ${ }^{2}$, ALMAZBEK DOORANOV ${ }^{3}$, \\ MYKOLA SLYNKO ${ }^{4}$, OLEKSANDR MARCHENKO ${ }^{5}$, IRYNA SALIVONCHYK ${ }^{6}$ \\ ${ }^{1,6}$ Department of Finances, Banking and Insurance, LUTSK NATIONAL TECHNICAL UNIVERSITY, UKRAINE. \\ *E-mail: i.vakhovych@meta.ua \\ 2,3 Department of MBA Programs, KYRGYZ NATIONAL UNIVERSITY NAMED AFTER JUSUP BALASAGYN, UKRAINE. \\ 4,5 Department of Economics and Management, CHERKASY STATE TECHNOLOGICAL UNIVERSITY, UKRAINE.
}

\begin{abstract}
The article aims to study the international experience of smart specialization in regions and develop ways to improve it.

The work uses methods of systematization, morphological analysis, graphic and empirical research.

The authors investigated the essence, features and possibilities of smart specialization and schematically depicted it. The authors identified five principles of smart specialization, analyzed the foreign experience of smart specialization of regions. Based on the conducted studies of the European policy of unity and regional policy of the EU, they substantiated the expediency of introducing a model of smart specialization of regions to ensure sustainable regional development on an innovative basis and improve the living conditions of households.

Based on the studied theoretical and methodological material, the authors developed ways to improve the smart specialization of regions, namely, an algorithm for substantiation of potential areas of smart specialization in the regions and the conceptual approach to the choice of strategic priorities for innovative regional development, taking into account the principles of "smart specialization".

Recommendations are proposed for improving the processes of forming innovative regional strategies, taking into account the principles of the concept of "smart specialization", and the necessity of forming a map of unique, innovative competencies of regions and clusters of the country is substantiated.

To visually reflect the state of smart specialization of regions, the authors proposed the use of two maps that neutralize each other's shortcomings and help make more balanced management decisions.
\end{abstract}

Keywords: innovative development, modernizing, region, RIS3, smart specialization

JEL Classification: R11, R12, P25, 038

Received: 20 March 2021

Accepted: 6 April 2021 


\section{Introduction.}

The world is experiencing a period of significant change: globalization, automation, epidemics, crises. New technologies and digital technologies affect jobs, industrial sectors, business models, the economy and society as a whole. In such circumstances, one of the top priorities is the comprehensive support of EU member states and their regions in adapting to profound change, ensuring sustainable economic development and decent living conditions for European households. The European Commission identifies the opportunities and challenges facing Europe's citizens and regions [1]. In particular, the document states that "today, local issues have become global and global issues have become local more than ever. Therefore, anticipating and managing the modernization of existing economic and social structures, developing and implementing a long-term strategy that includes measures at all levels that lead to fundamental changes in technology, economy, and finance are the tasks identified as priorities for 2020. Such a strategy is a strategy of smart specialization, which involves identifying strengths and developing the competitive advantages of regions based on the existing structure of the regional economy and innovation and avoiding duplication of research and innovation by different regions. Studying the experience of EU countries, its implementation in the regions, development and implementation of own smart specialization strategies in the regions will increase regional competitiveness, create new jobs, improve living conditions of households, and receive additional financial opportunities to support regional development.

In modern conditions of a radical change in technology, the importance of national innovative economic systems is increasing dramatically. Innovation is inherently focused on a specific territory that has its own unique characteristics and comparative advantages. In this regard, the country's level of innovative development is largely determined by the level of development of innovative activities at the regional and local levels. In the near future, the key factor of competitiveness will be an economy's ability to implement innovations. Therefore, the transition to an economic model focused on innovation and services is a response to global challenges. Of course, the country's innovative economic system must be built on the basis of the formation of regional innovative economic systems.

In a global economy, many countries, regardless of their level of development, perceive innovation as a solution to problems. In this regard, close attention is paid to various instruments of regional development, such as the EU Research and Innovation Strategies for Smart Specialization (RIS3), which were originally implemented in the European Union (EU) and, as the practice has shown, are able to stimulate innovative activity in lagging regions. The rich experience of such strategies can serve as a lesson for dynamically developing states.

\section{Theoretical background.}

\subsection{Smart Specialization Features}

As a policy tool, the smart specialization model's conceptual structure and conditions for successful implementation are widely represented in the literature [2-6].

The concept of "smart specialization" was proposed in 2009 by the EU expert group "Knowledge for Growth" as a way to increase the attractiveness of European regions for investment by global companies in research and development (R\&D) and other activities [3; 7].

The term "smart" concerning growth and development was first used in the Europe 2020 strategy, which identified three key priorities for developing the European Union in response to the continent's serious structural problems (Fig. 1). 
Figure 1. The term "smart" concerning growth and development

\begin{tabular}{|c|c|c|}
\hline$\stackrel{\mathscr{U}}{ \pm}$ & smart growth & based on knowledge and innovation \\
\hline 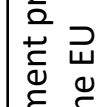 & sustainable growth & $\begin{array}{c}\text { promoting a more resource-efficient, green and } \\
\text { competitive economy }\end{array}$ \\
\hline $\begin{array}{l}\bar{d} \\
\frac{d}{0} \\
\frac{d}{2}\end{array}$ & inclusive growth & $\begin{array}{c}\text { stimulating an economy with a high level of } \\
\text { employment, ensuring economic, social and } \\
\text { territorial cohesion }\end{array}$ \\
\hline
\end{tabular}

To create niche competitive advantages, regions need to build capacity in the development of certain areas and technologies [8]. Smart specialization is designed to diversify the structure of the regional economy through the development of new core areas, which means to stimulate economic growth and job creation in the region. The basis for this is the cooperation of local authorities, science, business and civil society on a "bottom-up" basis.

Smart specialization is a relatively new concept that synthesizes Adam Smith's theories of division of labour and trade specialization, agglomeration and evolutionary economics. It is based on the principles of increasing returns on investment in science, the growing role of knowledge flow and the impact of market barriers on the development of regional advantages. Elements of theories of industrial development, flexible specialization and neoclassical social economics are used in part. As a "region-centred" economic model, RIS3 reflects state policy's contribution to stimulating investment in R\&D and innovation, the formation of scientific, technological and economic specialization, increasing competitiveness and productivity [3;9].

The main goals and key characteristics of RIS3 are systematized in Figure 2.

In rare cases, such specialization can arise spontaneously; most often, it becomes the result of targeted government efforts to support R\&D, transform production processes and create new activity areas.

\subsection{Smart Specialization Principles}

In the context of the Europe 2020 strategy, smart specialization is becoming a key element of a locally oriented innovation policy; it can be defined through the following five principles [10]:

1. Granularity. Smart specialization policies should target activities rather than sectors or firms. An example is companies looking at the potential of nanotechnology to improve the operational efficiency of the pulp and paper industry. In this case, the priority will not be the pulp and paper industry in general but activities that imply the development of nanotechnology applications for this industry. Targeted support for the development of new activities allows the government to simultaneously address two tasks: to improve the industry's efficiency and create capacity (including the knowledge base) for diversification into new areas.

2. Entrepreneurial discovery. The second innovation is the process of entrepreneurial discovery: entrepreneurs are continually looking for, finding and evaluating new business opportunities; this process is called entrepreneurial discovery. This is the approach that policymakers at the regional level should be guided by - focusing on activities rather than sectors. Policymakers should look for entrepreneurial opportunities that will enable regional or national plans to be implemented. They must be able to distinguish simple innovations from discoveries that have the potential to create new areas of specialization that can form the basis of a smart specialization strategy. 
Iryna Vakhovych, Baktygul Satyvaldieva, Almazbek Dooranov, Mykola Slynko, Oleksandr Marchenko,

Iryna Salivonchyk

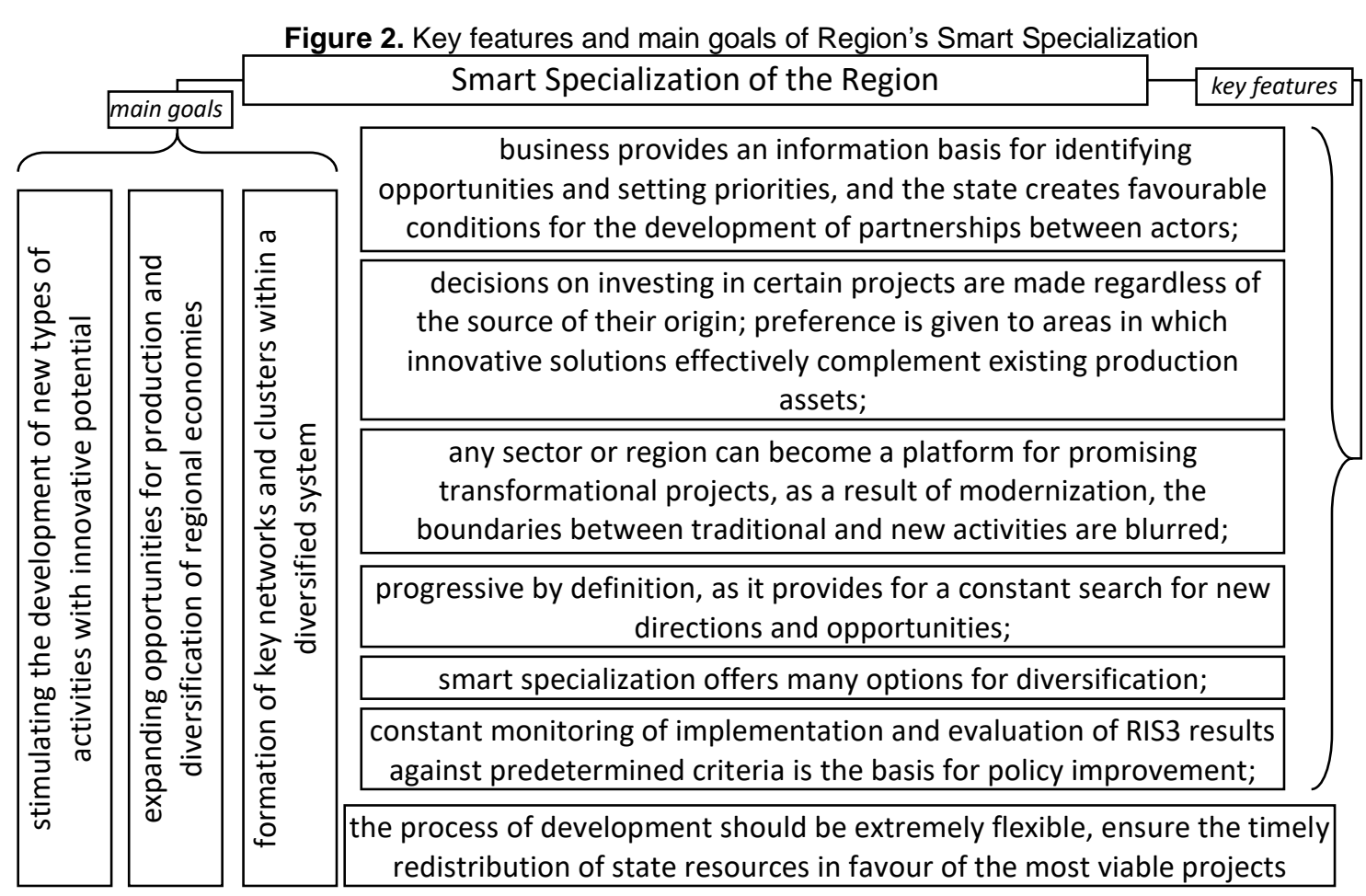

3. Specialized diversification. The third principle is that current priorities will not remain so forever. After four to five years, "new" activities will no longer be new. Whether they fail or mature successfully, they will no longer be the smart specialization strategy's priority areas.

4. Experimentation. The fourth new trait is experimentation. No line of business guarantees success; moreover, some undertakings are inevitably doomed to failure. The smart specialization strategy is based on experimental learning theory and develops the idea of self-realization proposed by Ricardo Hausmann and Dani Rodrik [Hausmann, Rodrik, 2003]. According to these authors, innovation policy should provide opportunities for experimentation to determine in practice what will and what will not work in a given context. Failure is a necessary element in finding successful solutions. The idea of discovery and experimentation is reminiscent of the role of indicators and evaluation.

5. Inclusive strategy. Smart specialization must be inclusive. This does not mean that such a strategy should include support for projects in all sectors of the economy; inclusiveness, in this case, means that each sector should have a chance to be included in the strategy if a good project is proposed.

\subsection{Foreign experience of smart specialization of regions}

The experience of the EU countries' regions that have joined the smart specialization platform is interesting in terms of improving the methodology for developing regional strategies.

Thus, in the strategies of innovative development of all Republic of Poland regions, as recommended by S3Platform, economic and innovation potential is considered through the prism of characteristics of regional assets, research infrastructure, clusters, benchmarking, research and production profile, specialization indicators and SWOT analysis. Simultaneously, in the methodology and presentation of the essential part of these units in the context of this country's regions, there is no single approach that corresponds to the basic principles of the methodology of smart specialization RIS3. In particular, the Strategy for the Development of Smart Specialization of the West Pomeranian Voivodeship, in addition to detailed analytically substantiated characteristics of production, economic and investment potential of the region, its assets (resources), strengths and weaknesses, as well as challenges and threats, According to this technique, the identification of 
potential niches of smart specialization is carried out through a comprehensive analysis, which includes two stages:

1) calculation of indicators that determine the critical mass of the analyzed foreign trade (or the structure of the region's economy);

2) calculation of indicators that reflect the main qualitative characteristics of each foreign trade.

The indicators of the first stage of the analysis determine the economic and innovative specialization of the region in terms of foreign trade and the level of entrepreneurial activity. The key advantage of specialization indicators is the relatively high degree of objectivity of the information obtained based on their calculation results, which is confirmed by a number of arguments.

The second stage of smart specialization analysis indicators reflects the level of competitiveness and innovation of enterprises, the development of science in favour of an innovative economy, and the structure of human capital in the context of innovation development. The task of this stage of analysis is a more detailed assessment of the key prerequisites for the smart specialization of the studied foreign trade.

Summarizing the review of the methodology used to develop the Strategy for the Development of Smart Specialization of the West Pomeranian Voivodeship, it can be stated that the key emphasis was placed on innovation and competitiveness of foreign trade scientific support and impact on socio-economic development of the region.

In its national strategy for intellectual specialization, Finland has focused on the development of smart cities. This initiative, called the Six Cities Strategy, addresses the need for sustainable urban development by exploring the strategic strengths of the six largest Finnish cities: Helsinki, Espoo, Tampere, Vantaa, and Oulu and Turku. Two EU-funded pilot projects have been launched: 1) robotic buses (SOHJOA) - the development of solutions for intelligent transport already operating in Helsinki; 2) Climate Streets - development and implementation of solutions to reduce greenhouse gas emissions and energy consumption in cooperation with local businesses, property owners, local communities and local authorities in the field of housing and transport.

In Lapland, smart specialization contributes to the development of the region's leading position in the exploitation and commercialization of Arctic natural resources while ensuring sustainable growth and job creation.

In the Extremadura region of southwestern Spain, local production of La Torta del Casar cheese, with the active participation of farmers, shepherds and other local entrepreneurs, has become a real asset of the region's smart specialization. As a result of this partnership, the Tajo-Salor-Almonte Local Rural Development Union has identified weaknesses in the production system and developed solutions to address them using information and communication technologies and other technological achievements in this field. Farmers and researchers address the lack of capacity to meet market demand during the peak season by jointly participating in a European network that develops high-tech agriculture.

In Romania's western region, the smart specialization strategy emphasizes the role of incubators and other business support structures in the development of entrepreneurship and the creation of innovative companies in the digital sector, where the region retains competitive advantage. The European Regional Development Fund has supported transforming a declining industrial area into a hub for digital development and creativity, integrated into the region's growing IT industry. In Timişoara, an incubator of startups has been created for beginners who want to start a business in the field of digital technologies. Young entrepreneurs receive logistics, as well as consulting and accounting services.

In summary, it can be argued that identifying promising areas of smart specialization of regions requires a comprehensive scientific approach that will systematically explore all sectors of the regional economy (in terms of foreign trade, their subspecies, industries, types of enterprises, etc.) 
through the prism of a wide range of local, national and global problems and challenges of the current and future development.

Formation and implementation of a regional marketing strategy in the system of state regulation of the regions of Kyrgyzstan. The region's marketing strategy is one of the key factors of its development, which allows achieving the integrated development of the regions, stimulating priority industries, and ensuring the attractiveness of the territory for target audiences. The main goal of the strategic development and marketing plan of the territory remains the achievement of successful sustainable development; to achieve the set goals, the competitive advantages of the region and possible directions of development in the use of resources must be determined.

Each region in Kyrgyzstan should be focused on developing its own marketing strategy, and the emphasis should be on the systemic nature of its formation and further implementation.

Therefore, based on the generalized experience of the regions of Kyrgyzstan and foreign marketing plans, a reference strategy is proposed as the complete set of elements applied in practice, capable of determining priority activities and the vector of movement of the region for the successful implementation of plans aimed at effective social and economic development.

The strategy aims to:

- to create an optimal model for regional development;

- to make the necessary conditions for improving the quality of all types of regional resources;

- to search for their potential consumers;

- positioning the region in the interregional division of labour.

In summary, it can be argued that identifying promising areas of smart specialization of regions requires a comprehensive scientific approach that will systematically explore all sectors of the regional economy (in terms of foreign trade, their subspecies, industries, types of enterprises, etc.) through the prism of a wide range of local, national and global problems and challenges of the current and future development.

\section{Results and discussion}

The "smart specialization" strategy is a promising logical continuation of the cluster approach to managing the development of the economy as a whole and at the regional level, which is now widely developed.

Based on the tasks, the justification of potential areas of smart specialization in the regions can occur in the following sequence (Fig. 3).

As a result of implementing the proposed conceptual approach, the regional innovation strategy should become an effective tool. At the same time, the priority of innovative development should be in all regions, and not only in the regions - innovative leaders. By focusing on the region's unique competencies and resources and taking into account the various trajectories of its development, the policy of "smart specialization" leads on a national scale to the differentiation of regional innovation strategies and, as a consequence, to their greater diversity.

According to the concept of "smart specialization", any region can follow the path of innovation; only this path will be specific for each region, depending on the existing conditions and development potential. As a result, the region concentrates either on traditional industries or chooses the path of forming new high-tech sectors of the economy. In addition, great attention should be paid to interregional cooperation.

The smart specialization concept helps regions improve their innovation strategies based on the benefits of multilevel governance. Moreover, such strategies should be strictly individual, considering the specific ecosystem of science and innovations of a particular region. This approach's essence is to form a regional strategy based on the advantages and potential of a particular territory. The 
proposed conceptual approach to the selection of strategic priorities for innovative regional development is shown in Fig. 4.

Figure 3. Algorithm for substantiation of potential areas of smart specialization in the regions $0 \sqrt{\text { vertical analysis of the structure of the regional economy by selected key indicators (in terms }}$

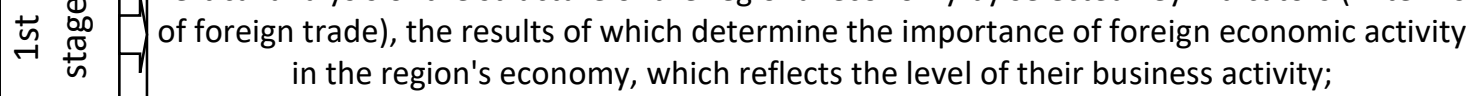

horizontal analysis of the state and efficiency of foreign trade according to the system of
indicators that characterize the structure of capital (basic, human, financial), the level of its
return and liquidity (in terms of large, medium and small enterprises);

sectoral analysis, which involves the calculation of narrow special indicators that reflect the 용 enterprises);

$\begin{gathered}\text { summarizing the vertical, horizontal and sectoral analysis by adding the values of the } \\ \text { calculated indicators for the current period and their dynamics for the last } 5 \text { years; }\end{gathered}$
and prospects for the operation of certain foreign trade in the region;

Figure 4. The conceptual approach to the choice of strategic priorities for innovative regional development, taking into account the principles of "smart specialization"

\begin{tabular}{|c|c|c|}
\hline \multirow{3}{*}{$R$} & Determination of glol & $\begin{array}{l}\text { bal technological trends in the industries of the current and } \\
\text { prospective specialization of the region }\end{array}$ \\
\hline & \multicolumn{2}{|c|}{ Identification and search of partner regions/clusters } \\
\hline & \multicolumn{2}{|r|}{ Taking into account global technological trends } \\
\hline \multicolumn{3}{|c|}{ Taking into account national trends in innovative development } \\
\hline \multicolumn{3}{|c|}{ Industry evolution (base technology, new product) } \\
\hline \multirow{3}{*}{\begin{tabular}{|c|} 
Selection of \\
priority \\
industries
\end{tabular}} & \multicolumn{2}{|c|}{ Industry modernization (new technology, old product) } \\
\hline & \multicolumn{2}{|c|}{ Diversification (the emergence of new industries related to existing ones) } \\
\hline & \multicolumn{2}{|r|}{ Rapid emergence and growth of new industries } \\
\hline \multicolumn{3}{|c|}{ Open innovation; user-induced innovation; social and service innovation. } \\
\hline \multirow{2}{*}{\multicolumn{2}{|c|}{$\rightarrow \begin{array}{c}\text { Identification of key competencies of } \\
\text { neighbouring regions/clusters to } \\
\text { identify areas of potential cooperation }\end{array}$}} & $\begin{array}{l}\text { Using the map of unique, innovative competencies of the } \\
\text { regions }\end{array}$ \\
\hline & & Using the country cluster map \\
\hline \multicolumn{2}{|r|}{$\begin{array}{c}\text { Formation of innovation clusters in } \\
\text { selected priority sectors }\end{array}$} & $\begin{array}{l}\text { The initiators of creating innovative territorial clusters can be } \\
\text { the state, large, small companies, research institutes and } \\
\text { universities. }\end{array}$ \\
\hline & & ce, monitoring of ways to improve \\
\hline
\end{tabular}


In this regard, the map of the regions' unique competencies and the country cluster map should become the essential tools for ensuring innovative development. The map of unique competencies of the regions assumes the disclosure of information on a particular region's selected development priorities based on the implementation of the concept of "smart specialization" and proposals for cooperation. Such a tool will make searching for potential partners more transparent and understandable and contribute to an increase in the number of interregional innovation clusters.

\section{Discussion}

To assess the state of smart specialization in a region, we offer a visual tracking map (Fig. 5).

The proposed representation of the state of smart specialization in the region has the main advantage - visibility and is suitable for the current monitoring of the process. However, for more accurate planning, evaluating results and making management decisions, we offer a diagram that reflects the ratio of the current status to the planned one (Fig. 6).

Such a presentation is not clear from the point of view of the indicators' essence, but it perfectly shows which indicators deviate from the plan. To level the disadvantages of both presentation methods, we suggest using them in pairs, especially since modern technologies allow the creation of such maps automatically.

Figure 5. Map of the state of smart specialization of the region

\begin{tabular}{|c|c|c|c|c|}
\hline \multirow{2}{*}{\begin{tabular}{|c|} 
Functional and \\
technological areas \\
of the region
\end{tabular}} & \multirow{2}{*}{ Indicator } & \multicolumn{3}{|c|}{ Status } \\
\hline & & Low & Medium & High \\
\hline \multirow{5}{*}{ 1. Society } & 1.1 Affordable additional education & & & \\
\hline & 1.2 Modern digital educational environment & & & \\
\hline & 1.3 New cadres of modern healthcare & & & \\
\hline & 1.4 Universities as centres of innovation space & & & \\
\hline & 1.5 Workforce for advanced technology & & & \\
\hline \multirow{3}{*}{ 2. Lifestyle } & 2.1 Formation of a healthy lifestyle & & & \\
\hline & 2.2 E-health & & & \\
\hline & 2.3 Technology and comfort - for mothers and children & & & \\
\hline \multirow{3}{*}{ 3. Economy } & 3.1 Export development & & & \\
\hline & $\begin{array}{l}3.2 \text { Increasing the level of provision of agricultural } \\
\text { products }\end{array}$ & & & \\
\hline & 3.3 Support for small and medium-sized businesses & & & \\
\hline \multirow{5}{*}{ 4. Environment } & 4.1 Reducing the negative impact on the environment & & & \\
\hline & 4.2 Development of alternative energy sources & & & \\
\hline & 4.3 Integrated development of single-industry towns & & & \\
\hline & 4.4 Formation of a comfortable urban environment & & & \\
\hline & $\begin{array}{l}\text { 4.5 Quality assurance of housing and communal } \\
\text { services }\end{array}$ & & & \\
\hline \multirow{3}{*}{ 5. Mobility } & 5.1 Safe and quality roads & & & \\
\hline & 5.2 Public transport tracking mobile applications & & & \\
\hline & 5.3 Autonomous vehicles messaging services & & & \\
\hline \multirow{3}{*}{ 6. Administration } & 6.1 Creation of a new model of a medical organization & & & \\
\hline & 6.2 Single portal of public services & & & \\
\hline & 6.3 Platform for government tenders & & & \\
\hline
\end{tabular}


Figure 6. Radar chart of smart specialization of the region

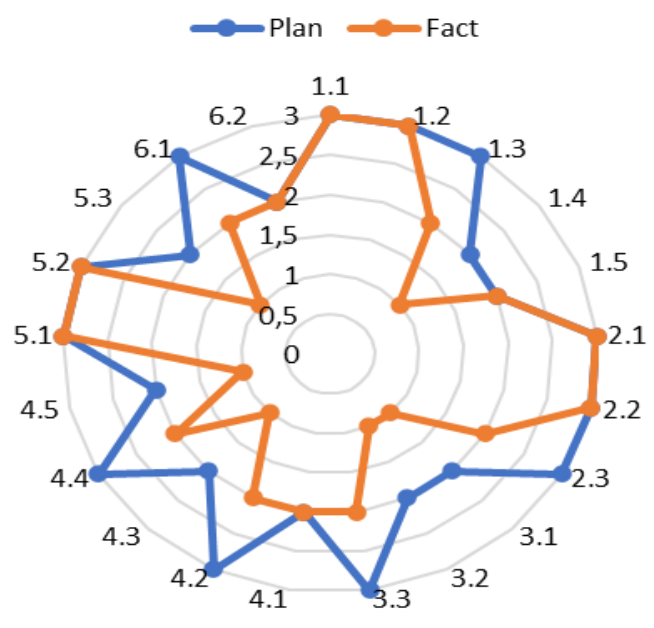

\section{Conclusions.}

Summarizing the above, we note that the concept of smart specialization involves the relationship between science, education and economics, although, in the context of regional development, we can instead talk about the relationship between business, science and society. According to these relations, the purpose of smart specialization is the optimal use of the potential of individual regions and countries through the maximum adaptation of possible directions of development of science and education in these regions or countries to their specific socio-economic conditions. That is, directing government intervention in such initiatives, activities and projects that allow specialization in the region or country or developing necessary technologies or products and services using these technologies.

Smart specialization regions can:

- to increase the innovative and competitive potential of areas as a basis for a model of sustainable growth;

- strengthen interregional cooperation, which is a key element of a globalized economy;

- draw attention to less developed regions;

- improve and enhance collaboration in the framework of EU innovation policies and programs.

Advantages that regions receive in the case of determining their own smart specialization and implementing the strategy accordingly:

- support for those types of economic activity that bring the most significant development, innovation and growth to the regional economy, as a result - the evolution of GRP and the improvement of other socio-economic indicators;

- increasing the investment attractiveness of the region by ensuring the formation of investors' understanding of which areas are most effective for investment in the region;

- expanding access to European programs;

- developing external sources of funding for the region's development through access to EU structural fund programs;

- enhancing the capabilities of the Euro regional partnership by identifying and establishing links with European regions with related specialization, joining European value chains;

- ensuring collegial development, adoption and implementation of strategic decisions through strengthening communication between regional stakeholders. 
Iryna Vakhovych, Baktygul Satyvaldieva, Almazbek Dooranov, Mykola Slynko, Oleksandr Marchenko,

Iryna Salivonchyk

Thus, the reasonable specialization of the region can become a powerful tool for modernizing innovation development.

\section{References}

1. Guide to Research and Innovation Strategies for Smart Specialisations (RIS3). URL: https://ec.europa.eu/jrc/sites/jrcsh/files/RIS3_GUIDE_FINAL.pdf

2. Bashynska, I. \& Dyskina, A. (2018). The overview-analytical document of the international experience of building smart city. Business: Theory and Practice, 19, pp. 228-241. https://doi.org/10.3846/btp.2018.23

3. Foray, D. (2015). Smart Specialization - Opportunities and Challenges for Regional Innovation Policy (1st ed.). London: Routledge.

4. Höglund, L., \& Linton, G. (2018). Smart specialization in regional innovation systems: a quadruple helix perspective: Smart specialization in regional innovation systems. R\&D Management, 48(1), pp. 60-72. DOI: 10.1111/radm.12306

5. Polishchuk, Y., Ivashchenko, A. \& Kornyliuk, A. (2020). Regional smart specialization: microbusiness impact. Baltic Journal of Economic Studies, 6(5), pp. 209-215. DOI: 10.30525/22560742/2020-6-5-209-215

6. Saha, N., Saha, T. \& Saha, P. (2019). Smart Specialization Strategy: Does It Really Foster Regional Competitiveness? Smart Specialization and Regional Competitiveness In book: Smart Specialization Strategies and the Role of Entrepreneurial Universities. DOI: 10.4018/978-1-52256152-1.ch005

7. European Commission. Smart Specialization - Strenghtening Innovation in Europe's Regions. Project Leaflet by Directorate-General for Regional and Urban Policy. Brussels: European Commission.

URL: http://ec.europa.eu/regional_policy/sources/docgener/guides/smart_spec/strength_innov_regio ns_en.pdf.

8. Foray, D. (2017) The Economic Fundamentals of Smart Specialization Strategies in book: Advances in the Theory and Practice of Smart Specialization. DOI: 10.1016/B978-0-12-804137-6.00002-4

9. Halynska, Y., \& Oliinyk, V. (2020). Modeling of the distribution mechanism for fuel industry enterprises' rental income in the system. State - region - enterprise. Journal of Advanced Research in Law and Economics, 11(2), pp. 370-381.

10. Foray, D. \& Goenaga, X. (2013) The Goals of Smart Specialisation. JRC Scientific and Policy Reports - S3 Brief Series № 1. Brussels: European Commission. URL:

https://s3platform.jrc.ec.europa.eu/documents/20182/115084/JRC82213_The_Goals_of_Smart_ Specialisation.pdf/f5908687-6a34-42d7-bfd1-735e882e3681 